\title{
Macroparticle Charging in a Pulsed Vacuum Arc Thruster Discharge
}

\author{
Filip Rysanek ${ }^{*}$ and Rodney L. Burton ${ }^{\dagger}$ \\ University of Illinois at Urbana-Champaign, Urbana, Illinois, 61801 \\ Michael Keidar \\ University of Michigan, Ann Arbor, Michigan, 48109
}

\begin{abstract}
A pulsed vacuum arc discharge emits a plasma as well as macroparticles in the form of micron-sized molten droplets of cathode material. Due to their trajectory and size, these macroparticles often pose a contamination threat for both spacecraft-based thrusters, and thin film deposition systems. The charge of these macroparticles was experimentally measured, and compared to a model based on thermionic electron emission at $\mathrm{T} \sim 2500 \mathrm{~K}$. The model predicts and the experimental results verify that the charge on the macroparticles is positive, as compared to the negative charge expected for a DC vacuum arc. Experimental results show a roughly quadratic dependence of particle charge on the particle diameter, with a $1 \mu \mathrm{m}$ diameter particle having a charge of approximately $1000 \times 1.6 \times 10^{-19} \mathrm{C}$. Model results show a roughly quadratic charge dependence for particles smaller than $1.2 \mu \mathrm{m}$ and a roughly linear dependence for particles greater than $2 \mu \mathrm{m}$.
\end{abstract}

\section{Nomenclature}

$\mathrm{A}=$ surface area of particle on witness plate; Richardson's constant $=1.20173 \times 10^{6} \mathrm{~A} /\left(\mathrm{m}^{2} \mathrm{~K}^{2}\right)$

$\mathrm{a}, \mathrm{b}=$ coefficients of $\mathrm{D}_{\mathrm{i}}$ to volume correlation

$\mathrm{d}=$ deflecting plate separation

$\mathrm{D}_{\mathrm{i}}=$ particle diameter after impact

$\mathrm{D}=$ particle diameter in flight

$\mathrm{j}=$ ion current density

$\mathrm{j}_{\mathrm{e}}=$ electron current density at the macroparticle surface

$\mathrm{j}_{\mathrm{eo}}=$ electron current density in the sheath

$\mathrm{M}_{\mathrm{p}}=$ mass of macroparticle

$\mathrm{M}_{\mathrm{i}}=$ ion mass

$\varphi_{\mathrm{p}}=$ particle Voltage

$\Phi=$ work function

$\mathrm{Q}_{\mathrm{p}}=$ coulomb charge of macroparticle

$\rho_{1}=$ density of liquid copper at $1083{ }^{\circ} \mathrm{C}, 8000 \mathrm{~kg} / \mathrm{m}^{3}$

$\rho_{\mathrm{s}}=$ density of solid copper, $8920 \mathrm{~kg} / \mathrm{m}^{3}$

$\mathrm{s}_{\mathrm{o}}=$ macroparticle displacement on the witness plate

$\sigma=$ electrical conductivity

$\mathrm{T}_{\mathrm{e}}=$ electron temperature

$\mathrm{T}_{\mathrm{p}}=$ macroparticle temperature

$\mathrm{V}_{\mathrm{p}}=$ volume of macroparticle

$\mathrm{v}_{\mathrm{x}}=$ axial velocity of macroparticle

$\mathrm{V}_{\mathrm{i}}=$ ion velocity

$\mathrm{V}_{\mathrm{o}}=$ Voltage between the deflecting plates

$\mathrm{Z}_{\mathrm{i}}=$ ion charge state

\footnotetext{
* PhD Candidate, Department of Aerospace Engineering, 104 S Wright St., Student Member AIAA.

${ }^{\dagger}$ Professor, Department of Aerospace Engineering, 104 S Wright St, Associate Fellow AIAA.

* Assistant Research Scientist, Department of Aerospace Engineering, 3038 FXB Building, Member AIAA.
} 


\section{Introduction}

$\mathrm{R}$ ecent years have seen a decrease in spacecraft size, along with a need for smaller propulsion systems. There is a wide range of available propulsion systems for satellites larger than $1000 \mathrm{~kg}$. Many of these scale down for use in smaller $100 \mathrm{~kg}$, or even $10 \mathrm{~kg}$ satellites. However, spacecraft weighing on the order of $1 \mathrm{~kg}$ have few propulsion options capable of providing orbit transfer, active attitude control, or even de-saturation of momentum wheels.

Among the few options that do exist are vacuum arc thrusters (VAT) ${ }^{1-3}$ These thrusters provide thrust by utilizing the high velocity ions ejected from the cathode of a vacuum arc. The reduced mass of these thrusters is achieved by using an inductive energy storage (IES) power processing unit. Figure 1 shows a simplified schematic of the thruster circuit.

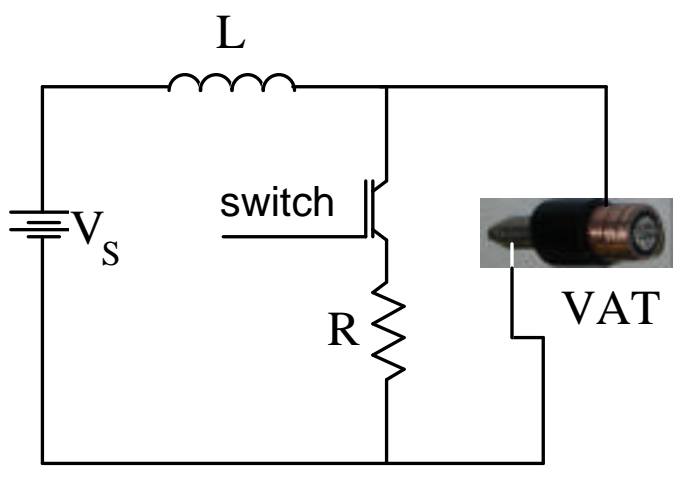

Figure 1 Schematic of the circuit used on a typical vacuum arc thruster

A semiconductor switch is triggered to draw current from the DC, low voltage power supply through an inductor. Once the switch is opened, a voltage peak of $\mathrm{L} \mathrm{dI} / \mathrm{dt}$ is produced, igniting a plasma by running current through a thin metal film coating between the two electrodes. ${ }^{4,5}$ Since these thrusters operate in a pulsed mode they can provide a wide range of thrust and $I_{s p}$ depending on cathode material, pulse frequency, pulse shape, geometry, and other variables.

The most recent version of the VAT is the magnetically enhanced vacuum arc thruster (MVAT). The inductor used to store the energy during operation is coiled around the thruster itself, providing a magnetic field which collimates the exhaust, reducing spacecraft contamination and increasing thrust by $50 \%$. In a recent study, the MVAT demonstrated an impulse bit of 2.7 $\mu \mathrm{N}$-s while firing at $50 \mathrm{~Hz}$ and 10 Watts. ${ }^{6}$ Although this thruster system (including PPU) weighs $1 \mathrm{~kg}$, future work will focus on mass reduction for use on even smaller satellites. An earlier version of the VAT weighing a total of $200 \mathrm{~g}$ has been incorporated into a $2 \mathrm{~kg}$ CubeSat satellite at the University of Illinois scheduled to launch in early 2006. ${ }^{7}$

At first glance, the vacuum arc of a VAT is a relatively simple phenomenon. However, the seemingly simple operation hides features that have been studied for decades and continue to be studied today. At moderate currents, the arc attaches to the cathode at individual spots, on the order of $10 \mu \mathrm{m}$ in diameter, while attaching to the anode as a diffuse plasma. ${ }^{8-10}$ Each cathode spot can support only a limited amount of current depending on the cathode material. ${ }^{11}$ When the current exceeds this value, (approximately $100 \mathrm{~A}$ for copper cathode) multiple cathode spots are formed simultaneously. Since the current travels though a micrometer sized area, the current density at the cathode surface within the cathode spots ranges from $10^{9}$ to $10^{12} \mathrm{~A} / \mathrm{m}^{2} .{ }^{12,13}$

The cathode spots emit electrons, ions, neutrals, and macroparticles in the form of molten droplets. Daalder showed that the number of ions emitted from the cathode is proportional to the total charge transfer, accounting for $7 \%-10 \%$ of the total arc current for a wide range of materials. ${ }^{14,15}$ The bulk of the current is conducted by electrons. The number of macroparticles increases with the pulse duration, ${ }^{15}$ and neutrals account for less than $1 \%$ of the total emitted flux. ${ }^{16}$ The ions emitted from a cathode spot are accelerated to high velocities ranging as high as $23 \mathrm{~km} / \mathrm{s}$, with copper ion velocities at $13.2 \mathrm{~km} / \mathrm{s} .{ }^{17}$ The mean ion charge state is 2.0 for copper, and generally higher than 1 for most materials. ${ }^{17}$ The electron temperature is usually not more than $1-2 \mathrm{eV}{ }^{8}$

The plasma of a vacuum arc is a complicated phenomenon. The electrons necessary to carry the current are extracted from the cathode by a combination of thermionic heating of the cathode surface, and field emission. When these two processes occur simultaneously in what is called thermo-field (TF) emission, the electron yield is increased non-linearly, allowing the vacuum arc to operate as it does. ${ }^{18}$ The cathode surface is heated by ions accelerated toward the cathode in the sheath. The cathode surface temperature is also enhanced by resistive heating of the arc current in the cathode. The field emission is enhanced by the electric field at the surface, generated by the space charge of the ions flowing toward the cathode. In this way, both conditions for TF emission are caused primarily by the ion flow toward the cathode surface. The ions are generated by the ionization of neutral vapor evaporated from the hot cathode spot surface, as well as macroparticle surfaces. ${ }^{18,19}$

The acceleration mechanism of the ions emitted from the cathode has been studied for decades as well. Initially, there were two schools of thought regarding the acceleration of the ions. One theory was that they were accelerated by the extreme pressure near the cathode spot,$^{20}$ enhanced by the friction drag force between the outward streaming electrons and ions. Another theory was that a potential hump was generated by the high ion concentration near the cathode, along with the higher mobility of the electrons. ${ }^{21-23}$ However, it was later shown that the two acceleration 
mechanisms were dependent on each other, and both added to the acceleration of the ions. ${ }^{24}$ Hantzsche calculated the contribution of the electric field, pressure gradient, and ion-electron friction to the acceleration of the ions, and concluded that each provides a comparable force, with ion-electron friction drag causing the largest contribution. ${ }^{8}$

\section{A. Macroparticles}

The macroparticles (MPs) emitted from the cathode are in the form of micrometer-sized molten metal droplets. The source of these droplets is a result of recoil from outward-directed ion jets acting on the molten surface of the cathode spot. ${ }^{25}$ McClure estimated that this mechanism could eject macroparticles from the surface at velocities ranging from 20 to $200 \mathrm{~m} / \mathrm{s}$. The measured velocity of the macroparticles ranges up to $800 \mathrm{~m} / \mathrm{s}$ with a peak around $200 \mathrm{~m} / \mathrm{s}$ as measured by a laser Doppler anemometer. ${ }^{26}$ It was also shown that the axial velocity of molybdenum macroparticles increases with instantaneous arc current, as well as axial location. Radial velocity increases only slightly with location within the arc. ${ }^{27}$ Qualitatively, this appears to be consistent with Ref. 19 which states that the macroparticles are accelerated by the momentum imparted on them by collisions with high velocity ions. Daalder's study of the exhaust mass of vacuum arcs ${ }^{15}$ has shown that the majority of macroparticles exit the cathode at a slight angle to the cathode plane. For Copper, peak macroparticle emission is approximately $10^{\circ}$ from the cathode plane, and $20^{\circ}-30^{\circ}$ for Cadmium. The study also showed that macroparticle size decreases with increasing angle from the cathode plane but increasing transfer charge increases the appearance of large macroparticles at large angles.

The macroparticles emitted from the cathode travel through the plasma and are thus subject to ion and electron collisions. The interaction of the plasma and macroparticles is described in Ref. 19. Each macroparticle in the plasma acts as a floating Langmuir probe, namely it will assume a potential necessary to assure zero net current to the macroparticle. Due to their high directed velocity compared to random velocity, the ions can be described as beamlike while the electrons are gas-like because their random velocity is much higher than their drift velocity.

Macroparticle charging and transport in vacuum arcs was studied by Keidar et al. ${ }^{28-29}$ The magnitudes of the MP charge predicted by the model at distances of about $10 \mathrm{~cm}$ from a $200 \mathrm{~A}$ cathode are between $10^{-17}-10^{-15} \mathrm{C}(100$ 10,000 positive electron charge). A model of the plasma jet - MP interaction was developed in order to calculate the drag force on MPs present in the plasma flow field. It was found that the collision cross section depends on the potential distribution in the MP vicinity. Under typical vacuum arc conditions the collision cross section is approximately the MP projected cross section. The MP velocities in the range of $300-1000 \mathrm{~m} / \mathrm{s}$ were predicted. It was shown that slow macroparticles could be electrically driven by electric field in the plasma near the cathode spot as well as by the sheath.

\section{B. Motivation}

One of the uses of vacuum arcs is the vacuum arc thruster described above. Due to their high scalability along with a small impulse bit these thrusters have potential as an electric propulsion system on a wide range of missions. However, one factor that has limited the use of electric propulsion in general has been the risk of spacecraft contamination. The ions emitted from electric propulsion systems usually have a very high directed velocity, limiting their contribution to spacecraft contamination. Macroparticles on the other hand, pose a spacecraft contamination threat. Macroparticles are emitted from the cathode at shallow angles, often making their direction of flight toward the spacecraft. They have a large mass which can disrupt optical instruments onboard. They are also composed of a conductive material which can damage electronic systems on board.

Another common use for vacuum arcs is vacuum arc deposition. This is the use of a vacuum arc to deposit a thin metallic film coating. ${ }^{30}$ The relatively high velocity of the ions emitted from the vacuum arc provides energetic depositing particles. The fact that ions are being deposited makes it possible for an electric field to be employed to accelerate or decelerate the ions, allowing for flexibility in the deposition energy. One of the prime difficulties in vacuum arc deposition is the appearance of macroparticles in the deposition layer. These macroparticles act to degrade the uniformity of the deposited layer. One way to reduce the number of macroparticles in the deposited film is by turning the ions $90^{\circ}$ with the magnetic field inside of a quarter-torus. ${ }^{31}$ This reduces the macroparticle number density along the centerline by a factor of 50 , but it is suspected that macroparticles electrically reflect from the walls of the chamber and continue to contaminate the deposition layer. Additionally increasing the magnetic field did not significantly change the macroparticle concentration on the centerline of the magnetic field. Experiments have shown that another method of reducing the number of macroparticles in the deposited film is to negatively bias the substrate. However, not all the macroparticles are reflected by the electric field, possibly due to macroparticle charging within the substrate sheath. ${ }^{32}$ Although both these methods reduce the number of macroparticles in the deposited film, the existence of any MPs still limits the usefulness of a vacuum arc deposition film.

One way to reduce macroparticle contamination on a spacecraft is to control their trajectory with electromagnetic forces. However, before a system can be designed with confidence, more needs to be known about the 
macroparticles. The velocity and size distribution of macro particles, including the direction of flight has already been studied. However, although there have been models developed, there is little if any experimental data on the charge of these macroparticles. This work is a study of the charge, mass, and velocity relationship of macroparticles from a vacuum arc.

\section{Experiment}

Multiple sources have indicated that the macroparticles coming from a vacuum arc are electrically charged. There is little experimental data in the literature to back up this assertion, and even less to determine the extent of the macroparticle charge. For this reason, an experiment was designed to determine the charge and velocity of macroparticles coming from a vacuum arc (or other macroparticle source) by deflecting macroparticles from their original trajectory, and measuring that deflection.

Consider a particle traveling through a perpendicular electric field as depicted in Fig. 2. The force exerted on the charged particle traveling through the electric field is the charge $\left(\mathrm{Q}_{\mathrm{p}}\right)$ times the electric field $(\mathrm{E})$. The initial velocity of the particle is $\mathrm{v}_{\mathrm{x}}$. After traveling in the electric field, the component of the velocity that is parallel to it is $\mathrm{v}_{\mathrm{y}}$. The electric field between two parallel plates each $l$ long, set $\mathrm{d}$ apart, and at voltages of $+/-\left(\mathrm{V}_{\mathrm{o}} / 2\right)$ is calculated as

$$
\mathrm{E}=\mathrm{V}_{\mathrm{o}} / \mathrm{d}
$$

The displacement of the macroparticle after the electric field $\left(\mathrm{s}_{\mathrm{o}}\right)$ is equal to:

$$
\mathrm{s}_{\mathrm{o}}=\frac{\mathrm{Q}_{\mathrm{p}} \mathrm{V}_{\mathrm{o}}}{2 \mathrm{M}_{\mathrm{p}} \mathrm{d}}\left(\frac{\ell}{\mathrm{v}_{\mathrm{x}}}\right)^{2}
$$

where $\mathrm{M}_{\mathrm{p}}$ and $\mathrm{Q}_{\mathrm{p}}$ are the mass and charge of the macroparticle respectively.

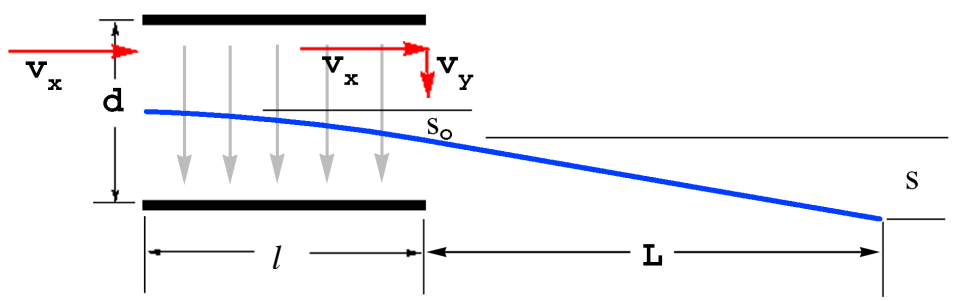

Figure 2 Schematic of Macroparticle trajectory through transverse electric field

If two $100 \mathrm{~mm}$ long parallel plates separated by $15 \mathrm{~mm}$ are charged to $+/-3750 \mathrm{~V}\left(\mathrm{~V}_{\mathrm{o}}=7500\right)$, we can produce an electric field of $5 \times 10^{5} \mathrm{~V} / \mathrm{m}$ transverse to the direction of flight. If a $0.5 \mu \mathrm{m}$ diameter copper macroparticle, charged to $8 \times 10^{-17} \mathrm{C}$ is traveling $200 \mathrm{~m} / \mathrm{s}$, this electric field will displace it by $2.9 \mathrm{~mm}$. This displacement is easily measurable by collecting the macroparticles on a witness plate.

The most important characteristic of the witness plate is that the surface be clean, flat and polished to make the collected macroparticles easily visible in a scanning electron microscope or optical microscope. Polished silicon wafers are readily available and come polished to within $\mathrm{nm}$ roughness. Silicon wafers have the added benefit of having a significantly different atomic weight than most metals considered for this study. This is usefully because the back scattered electron detector in the SEM shows a high contrast based on molecular weight. This simplifies the search for macro particles, and allows for the use of a lower resolution image to establish the location of the particles. 
In order to measure the displacement on the witness plate, the macroparticles coming from the vacuum arc must first be collimated or filtered to allow only certain MPs to impact the witness plate. This is done by firing the macroparticles through an orifice. The objective is to produce a distribution area of collected macroparticles on the witness plate that is relatively small. Theoretically, the smallest distribution that is possible with an orifice would occur if the orifice were infinitely small. In such a case, if the witness plate and cathode source were equidistant from the orifice, the distribution on the witness plate would be the size of the cathode itself, with the location of the macroparticle inside the distribution corresponding to the mirror image of the initiation point of the MP. If two orifices are used, the portion of the witness plate that is visible through the orifices becomes limited. This is done in order to reduce the chances that macroparticles generated by stray arcing away from the cathode result in a macroparticle on the witness plate. A schematic of this setup is shown in Fig. 3, where $d_{1}$ represents the width of the cathode and $d_{2}$ represents the image of the cathode or the macroparticle distribution on the witness plate. The diameters of the orifices are labeled $h_{1}$ and $h_{2}$, with $h_{1}>h_{2}$. The distance between the cathode and the first orifice is $l_{1}$, the distance between the second orifice and the witness plate is $1_{2}$.and the distance between the orifices is $\mathrm{s}$.

With the assumption that $h_{1}>h_{2}$, we can find the width $d_{2}$ according to the following Equation.

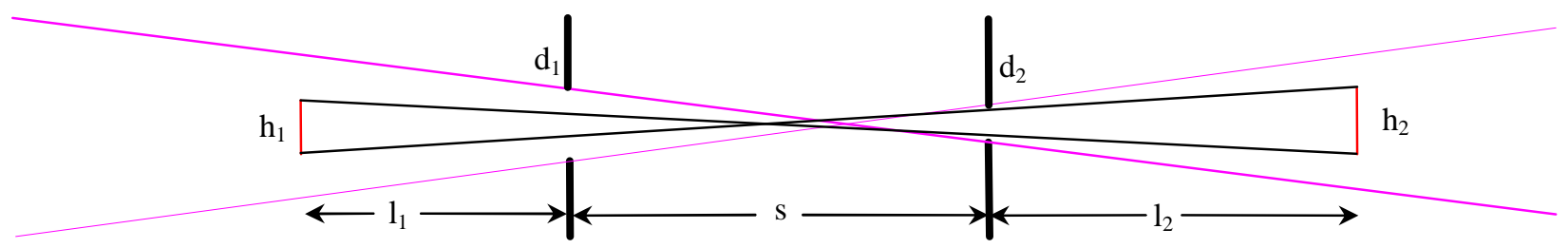

Figure 3 Schematic of the relationship between the orifices and line of sight in the experimental setup.

$$
\begin{aligned}
& \frac{\frac{\mathrm{h}_{1}}{2}+\frac{\mathrm{d}_{2}}{2}}{\mathrm{l}_{1}+\mathrm{s}}=\frac{\frac{\mathrm{h}_{2}}{2}-\frac{\mathrm{d}_{2}}{2}}{\mathrm{l}_{2}} \\
& \mathrm{~h}_{2}=\left(\frac{\mathrm{h}_{1}+\mathrm{d}_{2}}{\mathrm{l}_{1}+\mathrm{s}}\right) \mathrm{l}_{2}+\mathrm{d}_{2}
\end{aligned}
$$

By adjusting the location and size of the cathode, the size of the macroparticle distribution can be kept to a few millimeters. With the addition of an electric field after the second orifice, the macroparticles can be deflected sufficiently to measure their deflection from the original trajectory. Then, by determining the velocity and mass of the macroparticles, the charge of each MP can be determined.

\section{A. Thruster}

The vacuum arc for this experiment was generated by a derivative of a micro-vacuum arc thruster ( $\mu \mathrm{VAT})$. The $\mu \mathrm{VAT}$ was designed to provide attitude control to micro and nanosatellites. It can be designed in a number of geometries including a coaxial, layered sandwich, as well as a ring geometry. Due to its ease of construction, the sandwich or BLT geometry was used for this experiment. This geometry uses layers of flat sheets to comprise the different components of the thruster and was used on the UIUC Cubesat ION satellite. The first layer in this thruster is the cathode which is also the structure of the satellite. The cathode is separated from the anode by a ceramic insulator. This insulator is coated with a thin film to help initiate the breakdown. Past the anode is another insulator separating it from an aluminum layer used to hold the layers together. Figure 4 is a CAD representation of

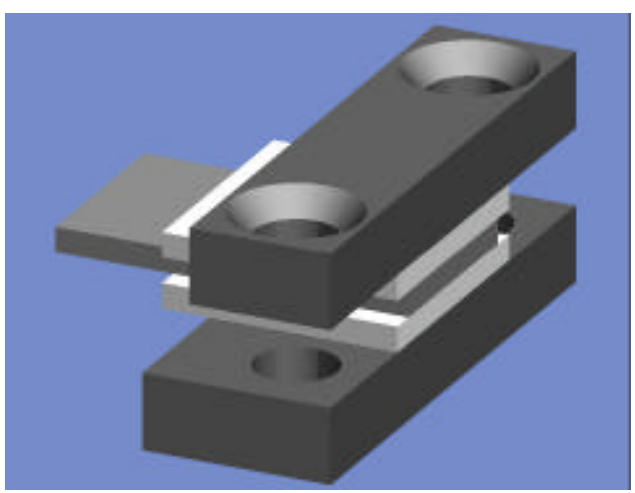

Figure 4 Schematic of the micro-vacuum arc thruster used on UIUC Cubesat ION this thruster. 
This thruster design is used with the small inductive power supply described earlier, making it suitable for small satellites. However, the thruster performance is sensitive to the thickness of the thin metal film coating the ceramic between the anode and the cathode. For this experiment, the design of the thruster was modified to include a trigger electrode. The layers of this lab thruster are as follows:

1) Insulated structure

2) Insulating high alumina ceramic

3) Cathode (copper)

4) Alumina silicate ceramic

5) Trigger electrode (copper)

6) Insulating high alumina ceramic

7) Anode (aluminum)

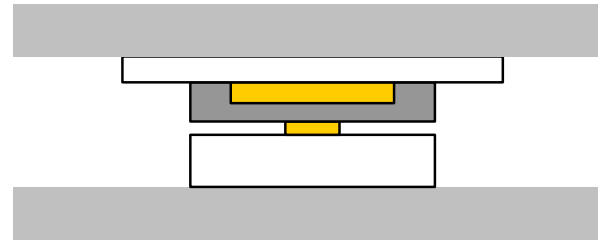

Figure 5 Front view of vacuum arc thruster used in this work

Figure 5 is a schematic of the frontal view of the thruster, showing the different layers.

The power processing unit used in this lab thruster is different from the inductive energy storage circuit used in the flight models. Instead of storing the discharge energy in an inductor, it is stored in an eight stage pulse forming network (PFN). ${ }^{33}$ With $3 \mu \mathrm{F}$ capacitors charged to $-600 \mathrm{~V}$, and $30 \mu \mathrm{H}$ inductors, the PFN is designed to deliver 100 amps for $150 \mu \mathrm{s}$. The designed current of $100 \mathrm{amps}$ is intended to limit the number of cathode spots formed during a single pulse. ${ }^{11}$ A resistance of $2 \mathrm{Ohms}$ is placed in series with the discharge to match the impedance of the PFN. The resulting current pulse is shown in Fig. 6.

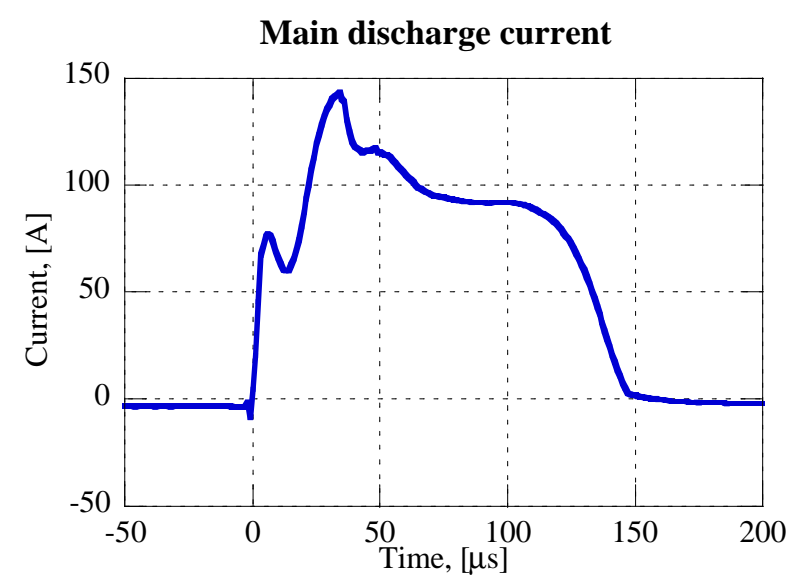

Figure 6 Current in the main discharge of the thruster, pulse rate $=8.5 \mathrm{~Hz}$

Trigger pulse current

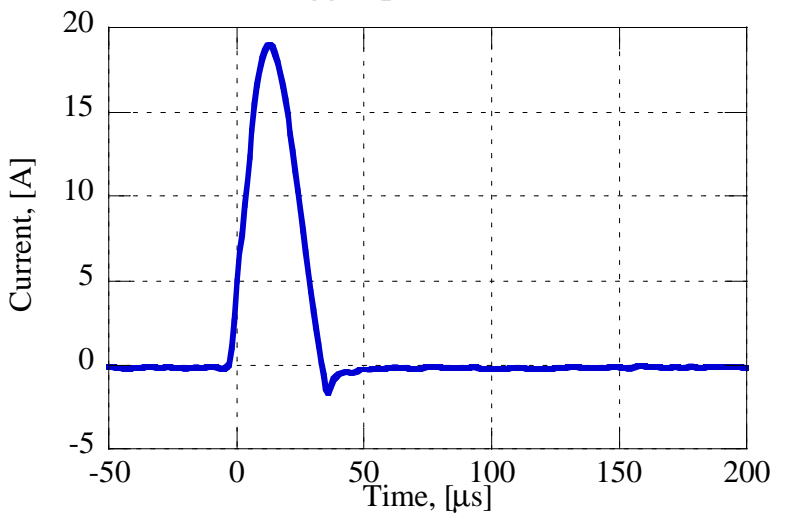

Figure 7 Current in the trigger pulse of the thruster
The triggering pulse is generated by discharging a 9.2 $\mu \mathrm{F}$ mica capacitor through a transformer. With the capacitor charged to $-600 \mathrm{~V}$, the transformer produces a $16.7 \mathrm{kV}$ potential across an open circuit. This voltage is sufficient to initiate the breakdown between the trigger electrode and the cathode, producing a plasma to initiate the main discharge between the cathode and anode. Figure 7 shows the trigger pulse current. This setup is similar to the setup used by Brown et al. in Ref. 34. The trigger pulse is generated by a firing circuit which closes a silicon control rectifier (SCR) to send the current to the transformer

The double orifice assembly used in this experiment is in a pair of boron nitride plates with a $0.53 \mathrm{~mm}$ diameter hole in the first plate and a $0.51 \mathrm{~mm}$ diameter hole in the second. The plate is countersunk so it is approximately 0.5 $\mathrm{mm}$ thick in the hole location.

The witness plate is a $20 \mathrm{~mm}$ tall by $30 \mathrm{~mm}$ wide section of a diced silicon wafer. The wafer used is a P-type Si:B wafer with a $5-25 \mathrm{ohm}-\mathrm{cm}$ resistivity. The witness plate is mounted into a holder which was designed to allow the removal and reattachment of the witness plate in the identical location. The reproducibility of the witness plate location will be shown in the results section. The witness plate is $116 \mathrm{~mm}$ past the second orifice, and 135 $\mathrm{mm}$ past the first.

Due to the finite orifice diameter and the location of the witness plate with respect to the orifice, the distribution on the witness plate is expected to be larger than the original. The width of the distribution on the witness plate $\left(h_{2}\right)$, calculated by using Eq. (3) for the conditions for this experiment (listed in Table 1), is 1.9 $\mathrm{mm}$.

The electric field used to divert charged particles after they travel through the orifices is generated by charging two $98 \times 25 \mathrm{~mm}$ parallel plates to opposite polarities. They

6

American Institute of Aeronautics and Astronautics 
are placed in a Delrin holder, which keeps the plates from arcing to the ground plane above or below.

According to Daalder, ${ }^{15}$ the angle at which macroparticles exit the cathode surface depends on the material. For copper, the angle at which the most macroparticles exit is between $5^{\circ}$ and $15^{\circ}$ from the cathode plane. For this reason, the thruster was tilted to an angle of approximately $40^{\circ}$ to the ground plan, in the hopes of increasing the number of macroparticles emitted in the direction of interest. A smaller angle, which might further increase the number of macroparticles would also increase the chance of arcing to the ground plane instead of the anode. This layout is shown in Fig. 8.

The thruster, orifices, witness plate, and electric field plates are all placed onto a grounded aluminum plate. Once the electric field plates are aligned, another aluminum plate is attached on top of the experiment downstream of the orifices. This is to ensure a uniform electric field, without a potential gradient dominated by a single ground plane. This entire assembly, along with the transformer is placed into the vacuum tank. Figure 9 is an overall schematic of the thruster setup.
Table 1. List of variables used to calculate the width of the macroparticle distribution

\begin{tabular}{|l|l|l|}
\hline & Description & $\begin{array}{l}\text { Value } \\
{[\mathbf{m m}]}\end{array}$ \\
\hline $\mathrm{h}_{1}$ & width of the cathode & 0.8 \\
\hline $\mathrm{l}_{1}$ & distance from cathode to first orifice & 90 \\
\hline $\mathrm{s}$ & distance between the orifices & 19 \\
\hline $\mathrm{l}_{2}$ & $\begin{array}{l}\text { distance from second orifice to the } \\
\text { witness plate }\end{array}$ & 116 \\
\hline $\mathrm{d}_{1}$ & diameter of first orifice & 0.53 \\
\hline $\mathrm{d}_{2}$ & diameter of second orifice & 0.51 \\
\hline $\mathrm{h}_{2}$ & $\begin{array}{l}\text { width of the particle distribution on } \\
\text { witness plate. "cathode image" (calc.) }\end{array}$ & 1.9 \\
\hline
\end{tabular}

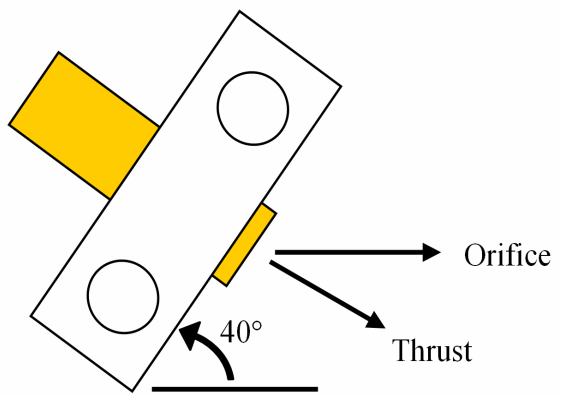

Figure 8 Side view of thruster showing thrust direction and location of orifice.

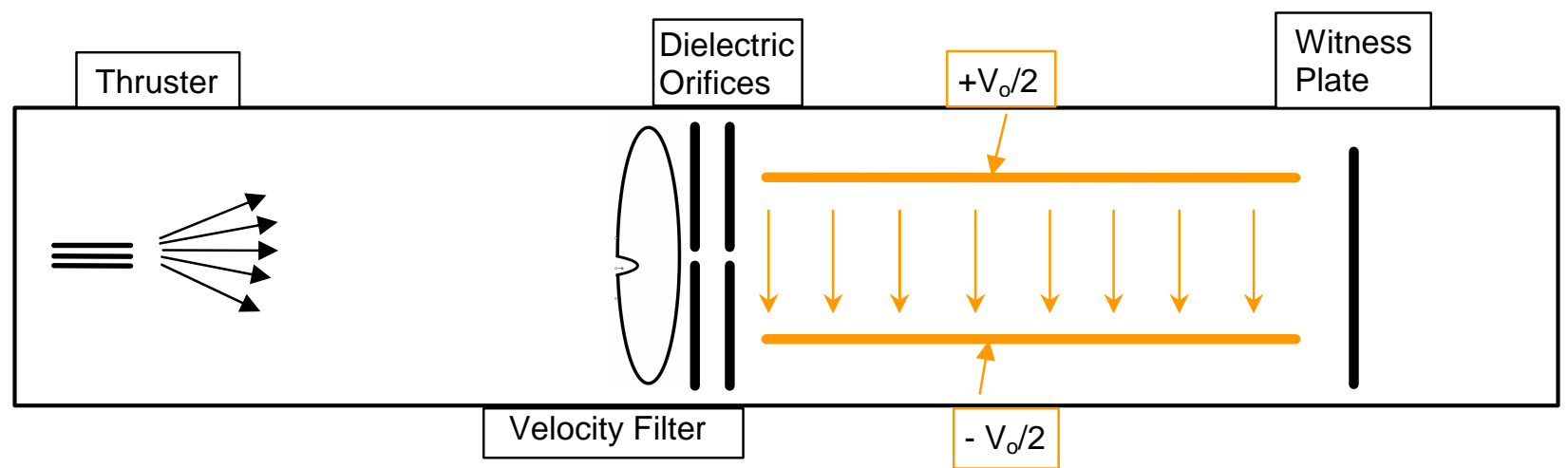

Figure 9 Schematic of the overall experimental setup

\section{B. Velocity Filter}

The velocity of the macroparticles is determined by using a time-of-flight velocity filter to allow particles within a certain velocity range to reach the witness plate. The velocity filter operates by only allowing particles to pass through the filter and orifices during a short window of time after the current pulse. The velocities that are transmitted are primarily determined by the delay between the thruster current pulse and the opening window. Particles traveling too fast will reach the velocity filter before the window is open, while particles traveling too slowly will arrive after the window has closed.

The velocity filter produces this window opening by blocking the entrance to the orifice with a spinning slotted disk. When the slot is in line with the entrance to the orifice, particles can proceed through the filter. By adjusting the spin rate, the width of the slot, and the time when the thruster is fired, the velocity of particles that will pass through the filter can be adjusted. Figure 10 shows a schematic view of the velocity filter setup.

If the time when a particle is generated were precisely known, then the velocity filter could be designed to allow all the particles traveling at a certain velocity range, and obstruct all those traveling faster or slower. However, even if 
we assume the macroparticles are generated some time during the $140 \mu$ s current pulse, particles traveling some velocities will only make it through the filter depending on when during the current pulse they were generated.

If we know the probability distribution of generating a macroparticle throughout the pulse, then we can calculate the percentage of particles that are transmitted through the velocity filter. For any given velocity, the percentage of particles that will make it through the filter is equal to the percentage probability that the particle was generated at a time during the pulse, when it will reach the filter during that opening window. Figure 11 shows the fraction of particles that will make it through the velocity filter for 4 different delay times between the current pulse and the opening window. The figure assumes that the probability distribution of generating a macroparticle throughout the pulse is constant and is based on the characteristics in Table 2.

Thruster

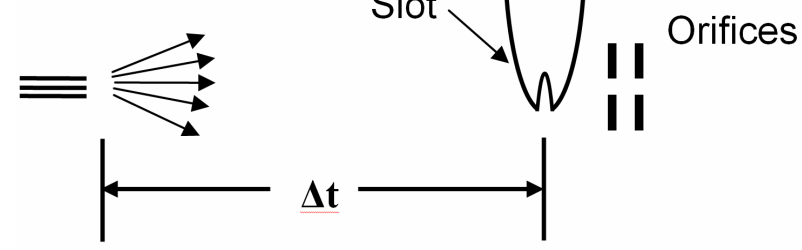

Figure 10 Schematic view of the velocity filter setup and operation From this figure the following information is used to describe the particle velocity for a given delay time.

The timing of the velocity filter is achieved by using a light and sensor pair to sense the location of the slot as it passes a point in its rotation. Once the slot passes the sensor, a timing pulse is triggered, which sends a second delayed pulse to the thruster firing circuit to fire the thruster. The delay time listed in Table 3 and Fig. 11 is the amount of time between the end of the timing pulse and the time when the slot reaches the orifice.

A single test consists of firing the thruster at approximately $8 \mathrm{~Hz}$ for 200,000 shots. After some preliminary tests were performed to verify the repeatability of the alignment of the setup, four tests were performed to measure the charge on varying velocity macroparticles. Each of these test corresponds to the velocities listed in Table 3. After each test, the witness plates were scanned at 200x magnification using a scanning electron microscope. These images were then stitched together, and the location and size of each particle (in pixels) was recorded using particle analysis software ${ }^{35}$.

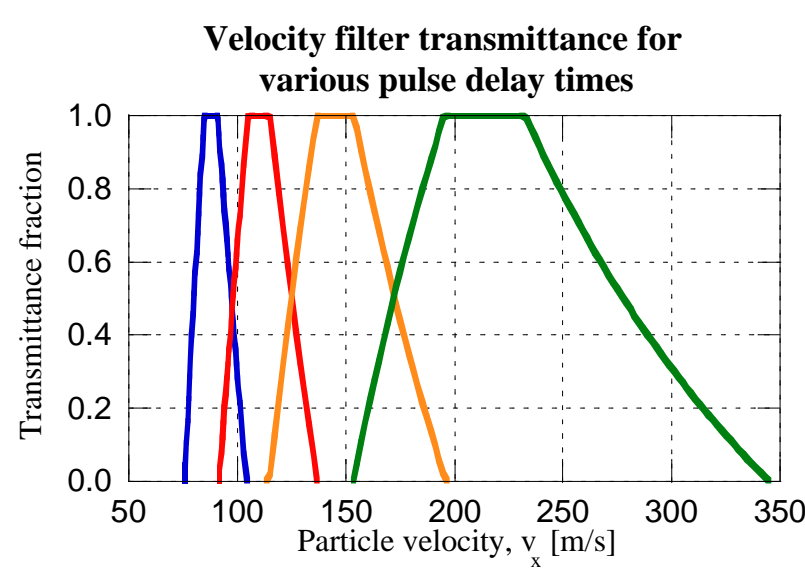

Figure 11. Fraction of particles allowed through the velocity filter, plotted for delay times $1100,870,640$, and $430 \mu \mathrm{s}$
Table 3. Physical characteristics of velocity filter

\begin{tabular}{|l|l|}
\hline spin rate & $3600 \mathrm{rpm}$ \\
\hline radius to the orifice & $4.68 \mathrm{~cm}$ \\
\hline slit width & $0.154 \mathrm{in}$ \\
\hline pulse width & $140 \mu \mathrm{s}$ \\
\hline distance to the velocity filter & $0.1 \mathrm{~m}$ \\
\hline
\end{tabular}

Table 2. Performance characteristics of the velocity filter used

\begin{tabular}{|l|l|l|l|l|}
\hline delay time $[\mu \mathrm{s}]$ & $\mathbf{1 1 0 0}$ & $\mathbf{8 7 0}$ & $\mathbf{6 5 0}$ & $\mathbf{4 3 0}$ \\
\hline velocity $[\mathrm{m} / \mathrm{s}]$ & 88 & 110 & 145 & 214 \\
\hline negative error $[\mathrm{m} / \mathrm{s}]$ & -8 & -12 & -20 & -42 \\
\hline positive error $[\mathrm{m} / \mathrm{s}]$ & +9 & +15 & +27 & +63 \\
\hline
\end{tabular}




\section{Experimental Results}

Below are some SEM images from various tests showing a wide range of macroparticles sizes (Fig. 12). The main macroparticle in Fig. 13 is approximately $16 \mu \mathrm{m}$ in diameter $\left(D_{i}\right)$, while some of the smaller MPs have a diameter less than $1 \mu \mathrm{m}$. Fig. 14 shows one such particle, but not the smallest in the image. Because of this large variation in size, relatively high magnification must be used during the sweep of the witness plate in order to detect the smaller macroparticles.
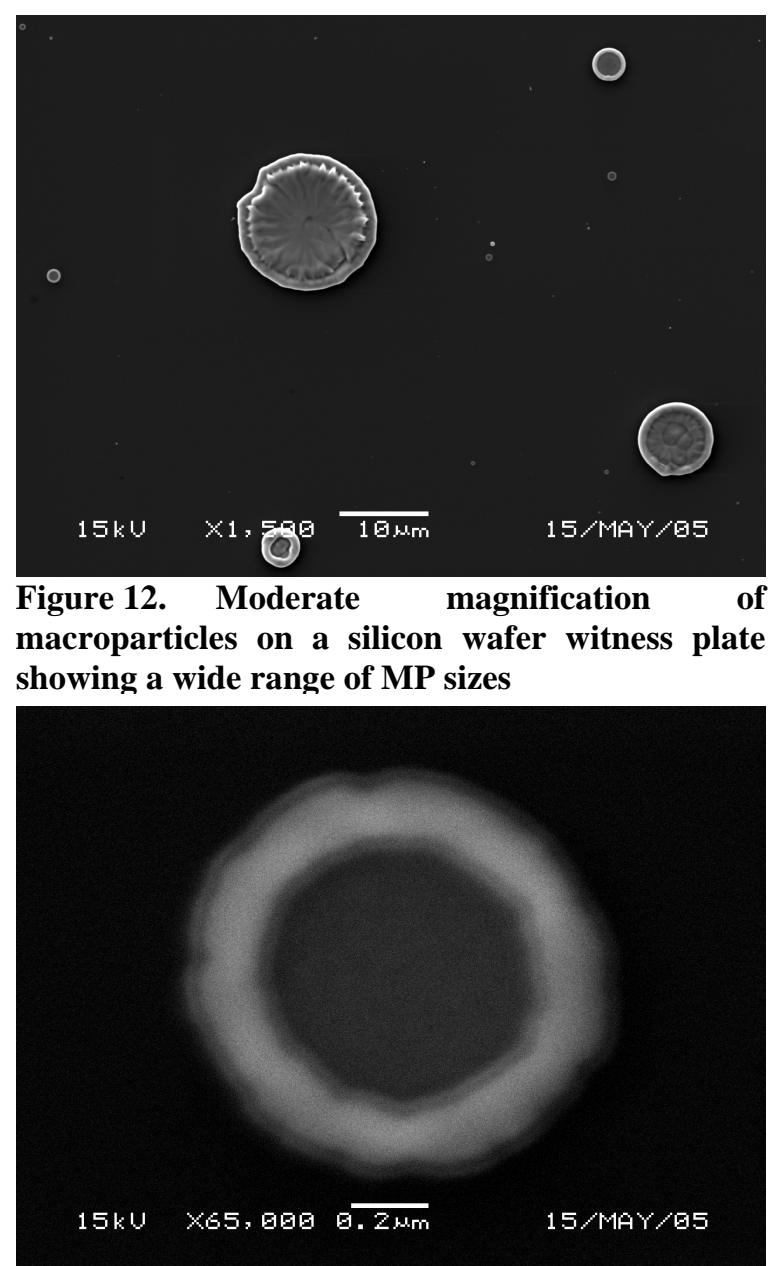

Figure 14 Very high magnification of a relatively small macroparticle

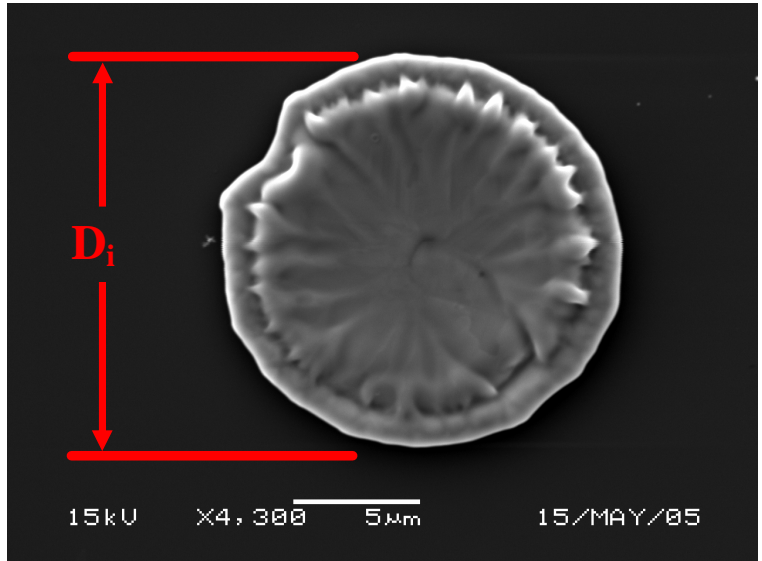

Figure 13 High magnification image of a relatively large macroparticle from Fig. 12

The shape of the macroparticles in the SEM images is consistent with the premise that the macroparticles are in the form of molten metal droplets when they impact the witness plate. The vast majority of the impacted macroparticles and almost all of the particles with a diameter less than $5 \mu \mathrm{m}$ have the shape of a flattened torus with a thin layer of material in the middle. However, the shape of the larger particles appears to vary slightly. For example, the particle in the bottom right of Fig. 12 appears to have the typical shape. The dominant particle in the center of the image appears to have an inverted shape where more material is in the center than along the edges. Finally, the particle at the bottom of the image has the shape of a torus, but the aspect ratio, or thickness of the toroid to the diameter appears larger than the majority of the macroparticles. We hypothesize that this variation is due to a combination of particle velocity and temperature at impact.

To verify the repeatability of the setup alignment, two tests were run. Both tests collected particles without the use of the velocity filter, and without a deflecting electric field. The same witness plate was used for both tests, in order to compare directly the location of particles from the two tests. Figure 15 shows the particles collected during the two tests. This plot shows that the width of the distribution is slightly less than $2 \mathrm{~mm}$, which is approximately the $1.9 \mathrm{~mm}$ width expected from the geometry. 


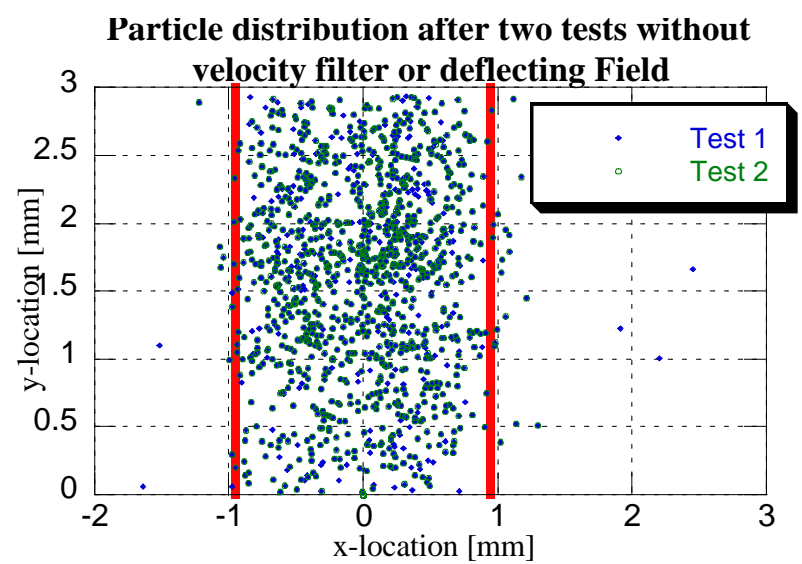

Figure 15. Collected particle distribution without an electric field or velocity filter from two tests.
The next four tests were performed with the velocity filter, as well as the deflecting electric field. For each of these tests, an electric field of $5.5 \times 10^{5} \mathrm{~V} / \mathrm{m}$ was used to deflect the particles. Figure 16 shows the size distribution of the particles plotted versus the $\mathrm{x}$ position on the witness plate for the four macroparticle velocities tested. The vertical red lines are separated by $1.9 \mathrm{~mm}$ and indicate the location of the particle distribution if no electric field were used. Each test was performed with the velocity filter set to allow a different range of velocities through. Note that the electric field is positive in the direction of the arrow.

The plots below clearly show that the particles collected on the witness plates have a positive charge and are deflected by the electric field. The plots also show that the larger particles were deflected less than the smaller
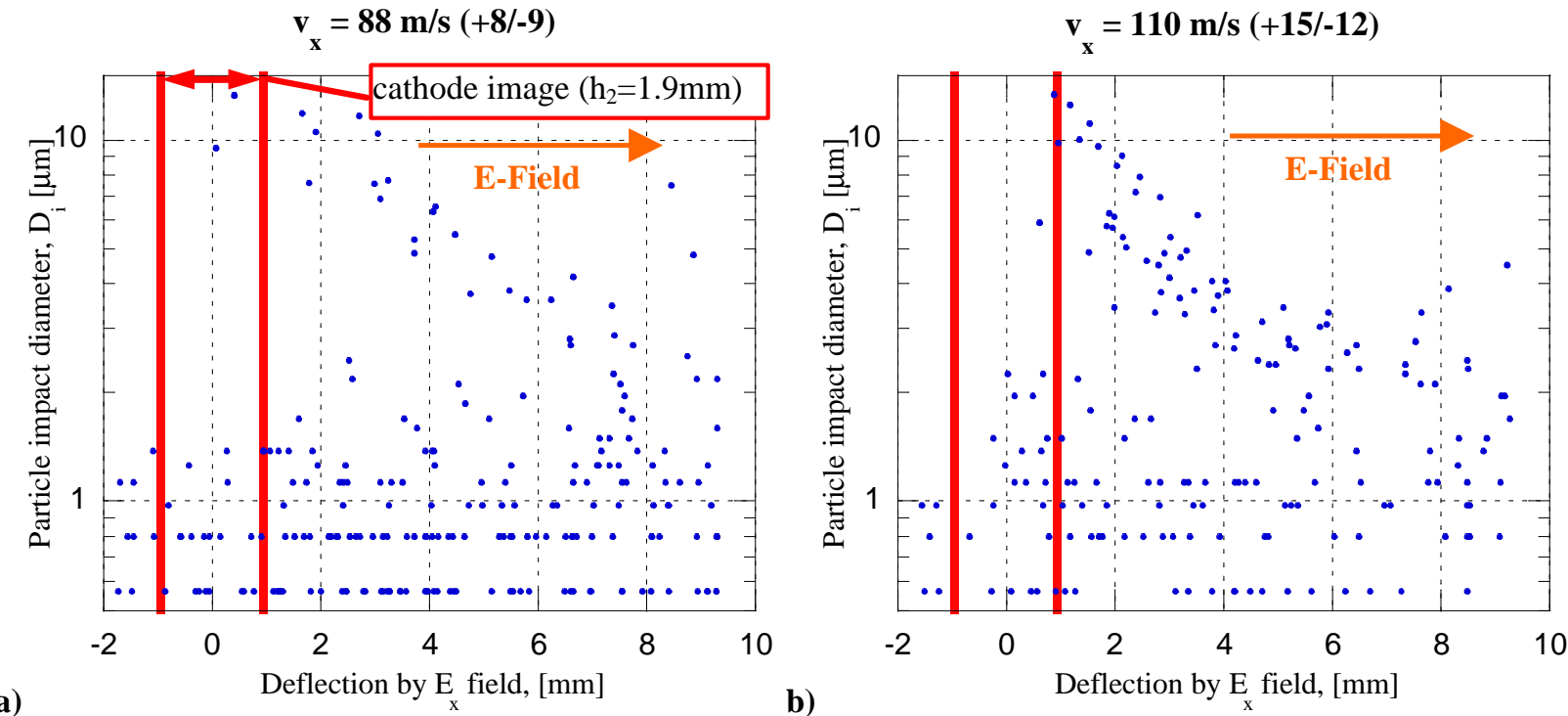

a)

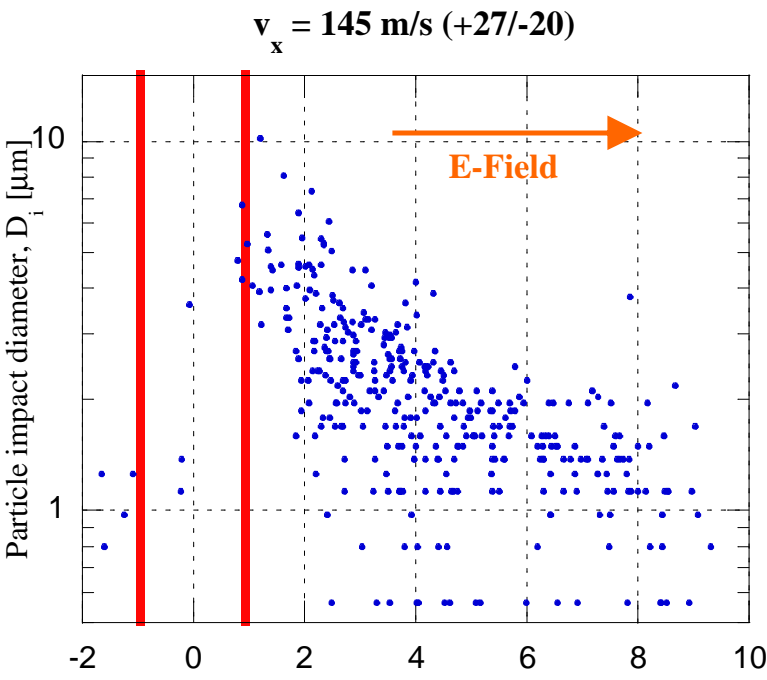

c) Deflection by $\mathrm{E}_{\mathrm{x}}$ field, $[\mathrm{mm}]$

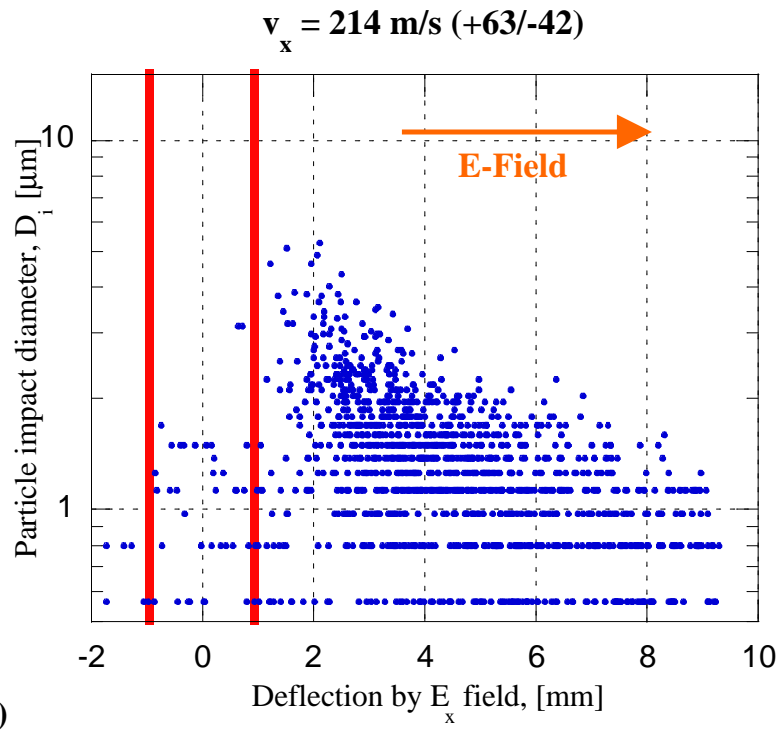

Figure 16. Collected macroparticle impact diameter plotted versus deflection due to the electric field for various particle velocities 
particles. In order to count the particles using the analysis software, the image has to be converted into black and white. This process introduces an error in the determination of the size of the impacted particles. For this reason, particles less than 6 pixels $\left(1.25 \mu \mathrm{m}^{2}\right)$, have a fairly large error bar associated with them.

Using Eq. 2 for the displacement on the witness plate, the relation for the charge of the MPs as a function of the mass $(\mathrm{m})$, velocity $\left(\mathrm{v}_{\mathrm{x}}\right)$ and displacement $\left(\mathrm{s}_{\mathrm{o}}\right)$ is:

$$
\mathrm{Q}_{\mathrm{p}}=2 \frac{\mathrm{s}_{\mathrm{o}} \cdot \mathrm{M}_{\mathrm{p}}}{\ell^{2} \cdot \mathrm{E}} \mathrm{v}_{\mathrm{x}}^{2}
$$

By estimating the volume $\left(\mathrm{V}_{\mathrm{p}}\right)$ of collected MPs from measurements taken of individual particles, ${ }^{15}$ Daalder generated a curve fit to correlate the measured outer diameter of the impacted particles to the volume of a macroparticle. We use this curve fit for copper shown in Eq. (5), to determine the volume of each macroparticle:

$$
\mathrm{V}_{\mathrm{p}}=\mathrm{aD}_{\mathrm{i}}^{\mathrm{b}}=0.178 \mathrm{D}_{\mathrm{i}}^{2.672}
$$

where the diameter $\left(D_{i}\right)$ is in $\mu \mathrm{m}$ and the volume $\left(V_{p}\right)$ is in $\mu \mathrm{m}^{3}$. The software used during our analysis of the SEM images gives us the number of pixels that each particle encompasses. This correlates to the surface area of the impacted macroparticle (A) in micrometers squared. Since the macroparticles show up circular in the SEM images, the diameter is calculated from (A) using the following equation.

$$
\mathrm{D}_{\mathrm{i}}=\sqrt{\frac{4 \mathrm{~A}}{\pi}}
$$

Combining Eq. (5) and (6), along with the volume of a sphere, results in a relation between the impacted surface area in $\mu^{2}$ and the diameter of the macroparticle during the flight. To get the actual flight diameter of the liquid copper, the volume is scaled by the ratio of densities of copper in solid to liquid form which introduces a diameter correction of $4 \%$. For this calculation, the density of copper in the liquid form (at $1083{ }^{\circ} \mathrm{C}$ ) is $8.00 \times 10^{-15} \mathrm{~kg} / \mathrm{\mu m}^{3} .{ }^{36}$ This particle diameter is then:

$$
\mathrm{D}=2\left(\frac{3}{4} \frac{\mathrm{a}}{\pi} \frac{\rho_{\mathrm{s}}}{\rho_{1}} 2^{\mathrm{b}} \pi^{-\mathrm{b} / 2}\right)^{1 / 3} \mathrm{~A}^{\mathrm{b} / 6}
$$

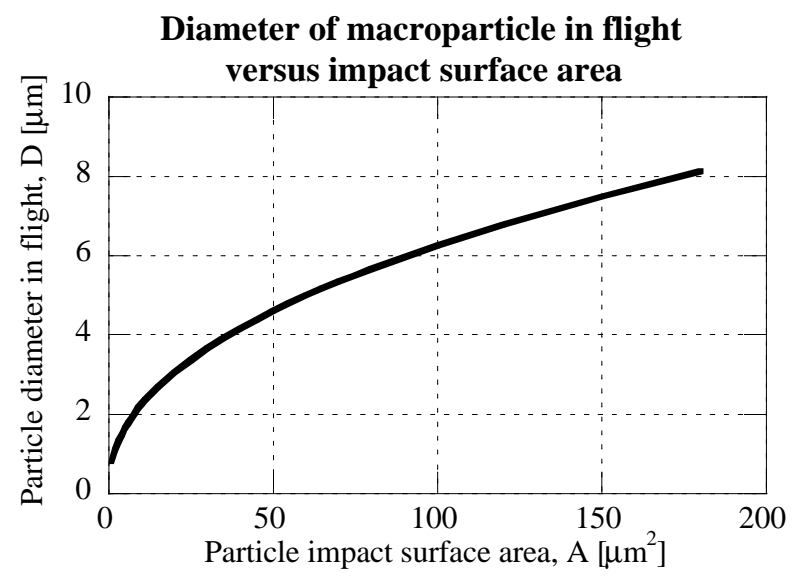

Figure 17 Relationship between impact surface area of collected macroparticle on the witness plate, and the diameter of the macroparticle in flight.
For the values of $\mathrm{a}$ and $\mathrm{b}$ in Eq. 5, this relationship is plotted in Fig. 17.

From Ref. 37, the density of solid copper $\left(\rho_{\mathrm{s}}\right)$ is $8.93 \mathrm{E}-$ $15 \mathrm{~kg} / \mu \mathrm{m}^{3}$ making the final mass as a function of impacted surface area:

$$
M_{p}=\rho_{s} V_{p}=\rho_{s} a_{i}^{b}=\rho_{s} a\left(\frac{4 A}{\pi}\right)^{b / 2}
$$

Combining with Eq. (4) above, we get a relation for the charge on the particle as a function of its transverse displacement from its original trajectory $\left(\mathrm{s}_{\mathrm{o}}\right)$ in meters, impacted surface area (A) in $\mu \mathrm{m}^{2}$, and velocity $\left(\mathrm{v}_{\mathrm{x}}\right)$ in $\mathrm{m} / \mathrm{s}$ :

$$
\mathrm{Q}_{\mathrm{p}}=2 \frac{\rho_{\mathrm{s}} \mathrm{d}}{\ell^{2} \mathrm{~V}_{\mathrm{o}}} \mathrm{a}\left(\frac{4}{\pi}\right)^{\mathrm{b} / 2} \mathrm{~s}_{\mathrm{o}} \mathrm{v}_{\mathrm{x}}^{2} \mathrm{~A}^{\mathrm{b} / 2} \text { coulombs }
$$


Using Eq. (9) the charge on each of the collected macroparticles is calculated and plotted in Fig. 18. The displacement $\mathrm{s}_{\mathrm{o}}$ is assumed to be the distance between the location of the particle on the witness plate and the midway point of the undisplaced particle distribution $(\sim 1.2 \mathrm{~mm})$. The electric field for each of the tests is $5.5 \times 10^{5}$ and the length of the electric field $l$ is $0.098 \mathrm{~m}$.
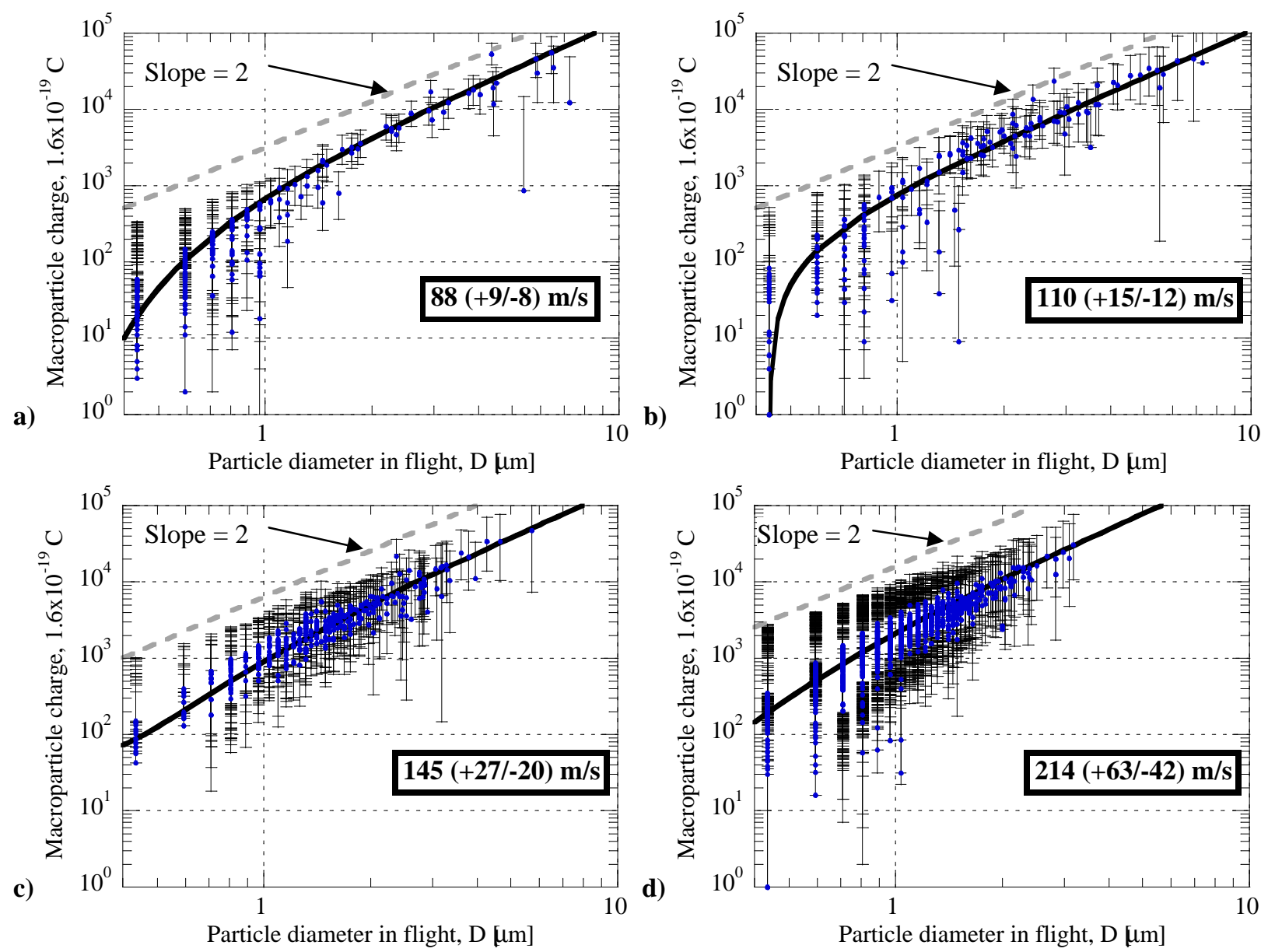

Figure 19. Accumulated macroparticle charge, plotted versus the particle diameter in flight for various velocities

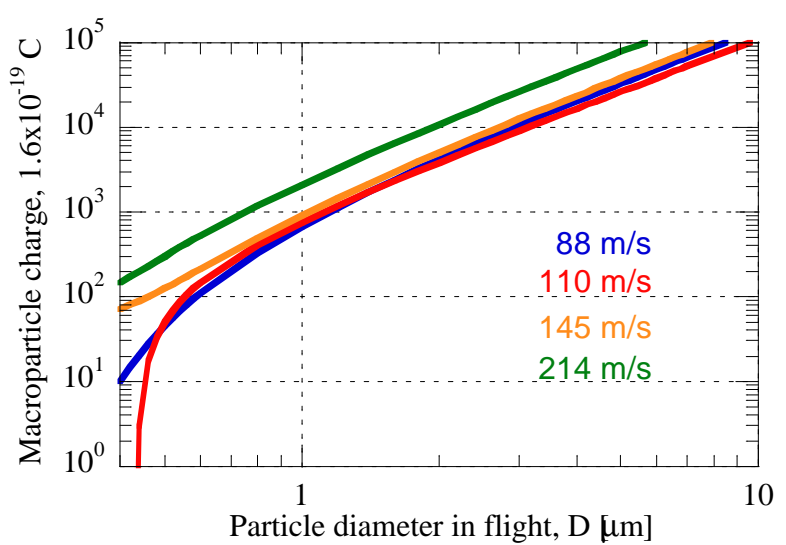

Figure 18. Curve fit of macroparticle charge, plotted versus diameter of particle in flight for all tested velocities
A quadratic curve fit of the form $\mathrm{C}_{2} \mathrm{x}^{2}+\mathrm{C}_{1} \mathrm{x}+\mathrm{C}_{0}$ has been used to show the trends of the data. Fig 19 shows the curve fits of all the data, plotted to show how they compare to each other. From the figure, it appears that the particles collected during the $214 \mathrm{~m} / \mathrm{s}$ test collected more charge than those in the other tests.

\section{A. Error analysis}

There are three major sources of experimental error in calculated charge:, the measured surface area A, the particle velocity $\mathrm{v}_{\mathrm{x}}$, and the error in the displacement. Other errors such as the value of the electric field and the variation in copper density as a function of temperature are negligible. As mentioned above, before the software can be used to locate and measure the size of the particles, the SEM images have to be converted to black and white. This involves setting a threshold value where a pixel brighter

12

American Institute of Aeronautics and Astronautics 
than the threshold is considered part of the particle, and pixels darker are not. This threshold value is different for each test, based on the contrast and brightness settings used in the SEM. The threshold is set in such a way that most of the background noise in the SEM images does not appear as particles. This process has the effect of slightly changing the perceived size of macroparticles. The number of pixels actually changed by this process per macroparticle is relatively small, but for small particles, it has a large effect on the calculated charge. At 200x, $1 \mu \mathrm{m}$ diameter corresponds to 4 pixels

The error in the velocity is based on the finite velocities that the filter allows through. Notice that as the velocities increase, the transmitted velocity distribution become wider. This is due to the short flight time of the particle $(\sim 350$ $\mu \mathrm{s})$ compared to the pulse duration $(\sim 150 \mu \mathrm{s})$. This is one of the reasons why there are many more particles in the 214 $\mathrm{m} / \mathrm{s}$ velocity case, as the $88 \mathrm{~m} / \mathrm{s}$.

The largest source of error, especially for the larger particles which were not displaced very much by the electric field, is the error in the displacement $\mathrm{s}_{\mathrm{o}}$. Some of the largest particles were displaced as little as $2-3 \mathrm{~mm}$. Since the error in that displacement is $+/-0.95 \mathrm{~mm}$ due to the size of the particle distribution as a result of the geometry of the setup, the error bars on the large particles become large.

There is also currently an inherent error in the fact that the relationship between the impacted surface area and the volume is not known precisely. The relationship currently used is from the literature for a similar experiment ${ }^{15}$. In the future, atomic force microscopy measurements will be taken to verify that the relation from the literature is accurate. This error could be the source of the discrepancy between the type of relationship between particle size and collected charge.

\section{Modeling of MP Charging in a pulsed vacuum arc}

Previous models of the MP charging have considered a steady state arc. Typically, electron and ion current density from the plasma are much higher than thermionic emission current density, and thus steady state charge accumulated by a MP traveling along the plasma jet is negative. However, in a pulsed vacuum arc, after discharge extinction, the ion and electron fluxes to the MP disappear while thermionic emission may continue due to high MP temperature. Depending on the pulse duration and MP temperature, this effect may lead to a change of the MP charge sign. In this section we describe a model for MP charging in the more general case of a pulsed vacuum arc. Several effects will be taken into account including MP charging, motion and temperature balance.

Following Ref. 38 the electric capacitance of a spherical particle is estimated as: $C=Q_{p} / \varphi_{p}=4 \pi \varepsilon R_{p}$, where $R_{p}$ is the MP radius and $Q_{p}$ is the MP charge. The MP charge evolution is calculated as $d Q_{p} / d t=I_{I}-I_{e},+I_{\text {the }}$ where $I_{i}$ is the total ion current, $I_{\text {the }}$ is the total thermionic current and $I_{e}$ is the total electron current collected by the MP.

In the case of a vacuum arc plasma jet, the ions have a directed energy larger than the MP potential and therefore can be considered to be beam-like, while the electrons are gas-like. Therefore the electron current is given by: $I_{e}=4 \pi R_{p}{ }^{2} j_{e}$, where $j_{e}$ is the electron current density at the MP surface. The electron current density absorbed by the MP depends upon the MP potential: $\mathrm{j}_{\mathrm{e}}=\mathrm{j}_{\mathrm{eo}} \exp \left(-\varphi_{\mathrm{p}}\right)$ if $\varphi_{\mathrm{p}}<0$ and $\mathrm{j}_{\mathrm{e}}=\mathrm{j}_{\mathrm{e} o \mathrm{e}} \exp \left(1+\mathrm{e} \varphi_{\mathrm{p}} / \mathrm{kT}_{\mathrm{e}}\right)$ in the opposite case, where $\mathrm{j}_{\mathrm{eo}}$ is the electron current density in the sheath and $T_{e}$ is the electron temperature. The ion current is given by: $\mathrm{I}_{\mathrm{i}}=\pi \mathrm{R}_{\mathrm{p}}{ }^{2} \mathrm{j}(1+\alpha)$ if $\alpha \geq 0$ and $\mathrm{I}_{\mathrm{i}}=\pi \mathrm{R}_{\mathrm{p}}{ }^{2}$ if $-1<\alpha<0$ and $\mathrm{I}_{\mathrm{i}}=0$ if $\alpha<-1$, where $\alpha=-2 \mathrm{Z}_{\mathrm{i}} \mathrm{e}_{\mathrm{p}} / \mathrm{M}_{\mathrm{i}} \mathrm{v}_{\mathrm{i}}{ }^{2}$ and $\mathrm{j}$ is the ion current density.

The current of thermionic emission is given by the Richardson-Duschman equation:

$$
\mathrm{I}_{\mathrm{the}}=4 \pi \mathrm{R}_{\mathrm{p}}^{2} \mathrm{AT}_{\mathrm{p}}^{2} \exp \left(-\frac{\mathrm{e} \Phi}{\mathrm{kT}_{\mathrm{p}}}\right)
$$

where $\Phi$ is the work function and $\mathrm{T}_{\mathrm{p}}$ is the MP temperature.

The following assumptions are used in the model: plasma density follows the current pulse which is assumed to be cosinusoidal, i.e. $\mathrm{N}(\mathrm{t}) \sim \cos (\mathrm{at})$. Plasma density decreases in the axial direction as

$$
\mathrm{N}(\mathrm{x})=\mathrm{N}_{\mathrm{o}} /\left(\mathrm{x} / \mathrm{R}_{\mathrm{o}}\right)^{2}
$$

with $\mathrm{N}_{\mathrm{o}}=10^{22} \mathrm{~m}^{-3}$ and $\mathrm{R}_{\mathrm{o}}=0.001 \mathrm{~m}$ (Ref. 39)We also assume that $\mathrm{T}_{\mathrm{e}}=2 \mathrm{eV} .^{10}$

Charging a MP to a positive potential with respect to the plasma will lead to a decrease in thermionic emission current. In essence, the positive MP potential acts as an effective work function and thus the MP potential is added to the work function in Eq. 10.

There are two primary forces on the MP: (i) a drag force due to collisions with neutral atoms and ions and (ii) a force due to the presence of the electric field in a current carrying plasma. In order to predict the MP axial velocity, 
$\mathrm{v}_{\mathrm{x}}$, we simply integrate the equation of motion from some starting point. Given the solution for plasma density and velocity distribution, we evaluate the forces that act on an individual MP. The equation of motion of an individual MP may be written as:

$$
\mathrm{d}\left(\mathrm{M}_{\mathrm{p}} \mathrm{v}_{\mathrm{x}}\right) / \mathrm{dt}=\mathrm{F}_{\mathrm{d}}+\mathrm{Q}_{\mathrm{p}} \mathrm{E}
$$

where $\mathrm{M}_{\mathrm{p}}$ is the mass of the MP traveling in the plasma. The first term is the total drag force and the second term is the electric force, which depends upon the electric field in the plasma and the MP charge, $\mathrm{Q}_{\mathrm{p}}$. An average electric field $E$ in the plasma may be evaluated from Ohm's law for known current density $j$ namely: $E=j / \sigma$. In partially ionized plasmas, there are Coulomb collisions of the MP with ions since the MP is charged. These collisions may result in a force, called ion drag. In these particular simulations we assumed a constant MP velocity in order to compare with experiment in which MP velocity filter was implemented.

As the particle moves through the plasma it is heated by neutral, electron and ion fluxes and is cooled by radiation. An additional cooling mechanism is due to decomposition of the dielectric material under high temperature. We will consider the situation where the internal thermal time constant is much shorter than the MP residual time. In this case, the MP has a uniform temperature throughout its volume and inward heat conduction from the surface may be neglected. The resulting energy balance reads:

$$
\frac{4}{3} \pi R_{p}^{3} \rho C \frac{d T_{p}}{d t}=4 \pi R_{p}^{2}\left(Q_{i, e}+Q_{n}-Q_{r}-Q_{d}\right)
$$

where $\mathrm{C}$ is the specific heat, $\rho$ is the density, $\mathrm{Q}_{\mathrm{i}, \mathrm{e}}$ is the energy flux associated with electrons and ions, $\mathrm{Q}_{\mathrm{n}}$ is the neutral particle energy flux, $Q_{r}$ is the radiation heat transfer, $Q_{d}$ is the energy losses to MP evaporation. We further simplified this model by neglecting MP evaporation. It should be noted that MP evaporation may be significant under certain conditions ${ }^{40}$ and will be considered in the future.

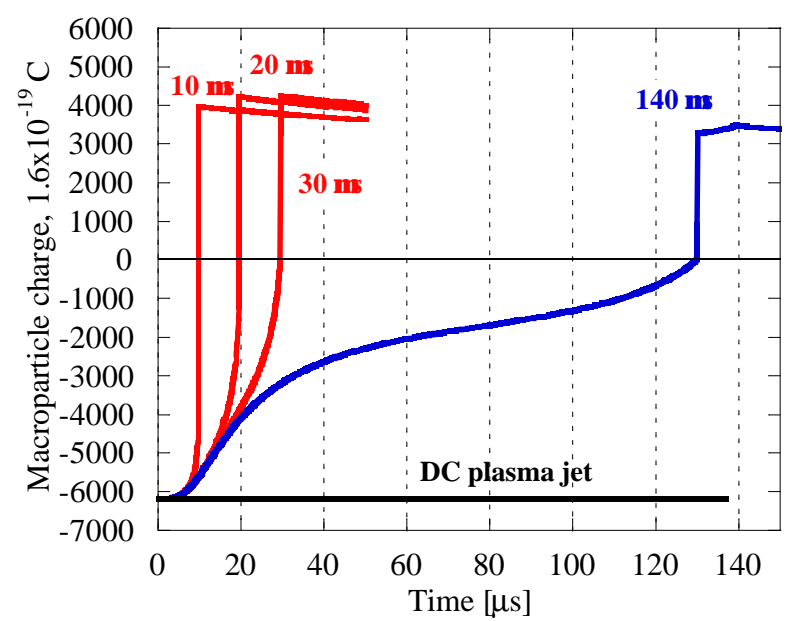

Figure 20 MP charge time evolution with vacuum arc pulse duration as a parameter.
The MP charge evolution is shown in Fig. 20. The Figure shows that after the end of the pulse, the MP charge increases sharply and saturates at a positive value corresponding to thermionic emission. MP cooling then leads to a decrease of the MP charge. The MP temperature evolution is shown in Fig. 21.

One can see that initially the MP temperature increases due to interaction with plasma. This effect is pronounced in the case of small particles and may lead to MP evaporation and radius decrease. However, after the discharge pulse is over, the MP temperature sharply decreases. This leads to MP charge saturation at a level which is limited by the MP potential with respect to the plasma.

According to the model prediction, the MP charge near the witness plate location (which is $20 \mathrm{~cm}$ from the cathode) linearly increases with MP diameter for large particles D>2 and quadraticly increases for small particles $\mathrm{D}<1.2$ as shown in Fig. 22. The figure also shows an increase in charge with the presence of a plasma, due to MP heating. 


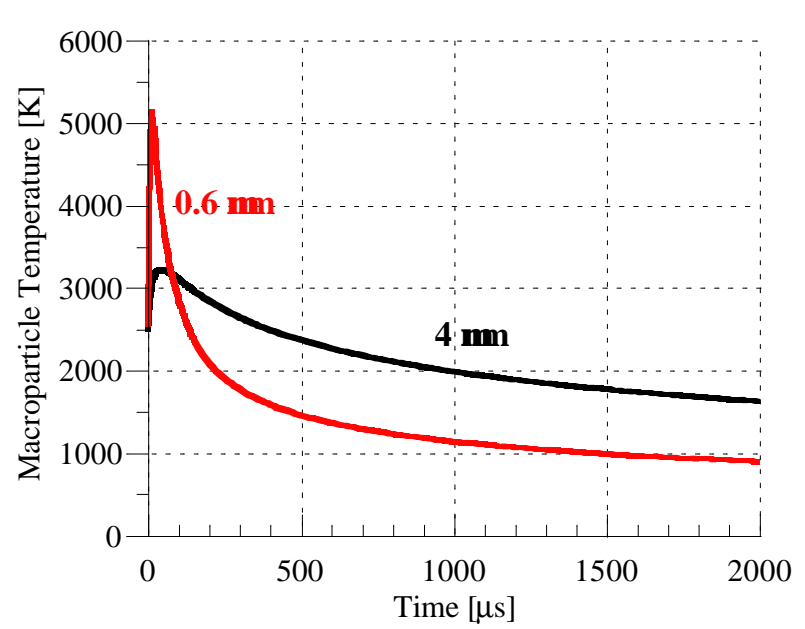

Figure 21 MP temperature evolution with MP radius as a parameter. MP initial temperature is $2500 \mathrm{~K}$.

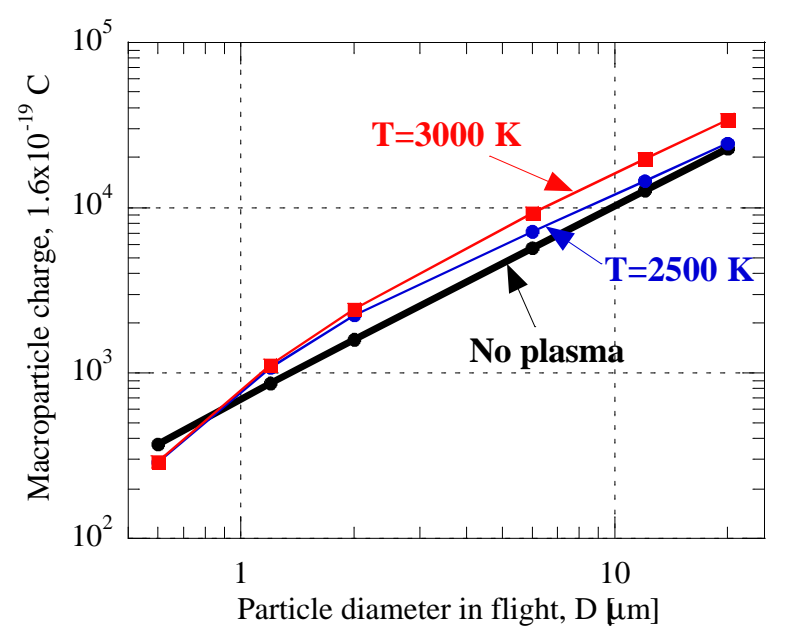

Figure 22 Quasi-steady MP charge as a function of MP radius for $0.2 \mathrm{~m}$ particle flight.

\section{Experiment vs. Theory Discussion}

Earlier models predicted that the charge on a macroparticle emitted from a vacuum arc would be negative. The model and experimental data described above show that for a pulsed vacuum arc, the MP charge is positive. The model incorporates the temperature evolution of the macroparticle as it is launched at $2500 \mathrm{~K}$ (Ref. 41), then heated by electron, ion, and neutral collisions, and cooled through radiation and thermionic emission. The charge evolution of the MP is determined by particle interaction with the electrons and ions, as well as thermionic electron emission. The work function used in the Richardson-Duschman equation (Eq. 10) is adjusted by the potential of the macroparticle to account for electrons that cannot escape the particle's Coulombic attraction. The results of this model are plotted against the experimental data as the red curve in Fig. 23. For moderately sized particles, the model

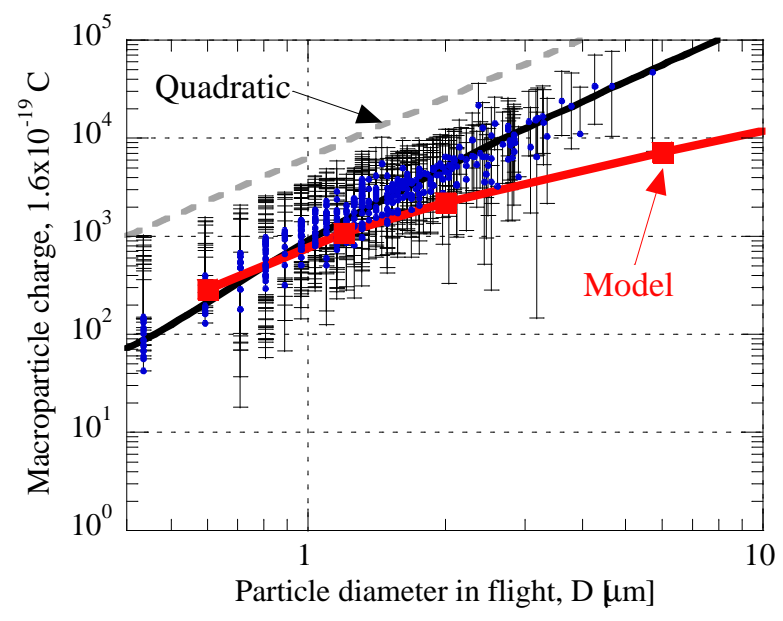

Figure 23 Comparison between model results for $\mathrm{T}=2500 \mathrm{~K}$ and experimental data for MPs traveling $145 \mathrm{~m} / \mathrm{s}$. predicts the collected charge to within the error bars of the experimental data.

The model predicts a roughly quadratic MP charge dependence on the diameter of the MP for particles smaller than $\mathrm{D}=1.2 \mu \mathrm{m}$, and a roughly linear dependence for particles larger than $\mathrm{D}=2 \mu \mathrm{m}$. The experimental data show a roughly quadratic dependence on particle diameter for all diameters. This discrepancy is not yet explained. However, the model does not take into account certain features which may significantly alter the comparison.

As the macroparticle is emitting electrons, some of those electrons escape the particle's attractive force, while others lack the energy to escape and are recaptured by the particle. This has the effect of producing an electron cloud around the macroparticle. This electron cloud is low density, with no electron-electron collisions. However, the cloud has the effect of shielding the exiting electrons from the charge on the macroparticle, making it easier for them to escape. As a result, the net electric field falls off faster than $1 / R^{2}$, increasing the number of electrons capable of escaping the macroparticle's Coulombic attraction.

The model also does not take into consideration the effect of the deflecting electric field on the electron emission. The electric field at the surface of a macroparticle of $\mathrm{D}=10 \mu \mathrm{m}$, is on the order of $10^{5} \mathrm{~V} / \mathrm{m}$. Since the deflecting field is the same order of magnitude, it could significantly affect the flight of emitted electrons.

Finally, from a model of the cathode spot, the temperature of the cathode at the center of the spot is $4000 \mathrm{~K}$, resulting in ejection of copper vapor, while at the outer diameter of the spot where the macroparticles are formed, the temperature is $2500 \mathrm{~K}$. For this reason, the temperature of the macroparticles has been assumed to be $2500 \mathrm{~K}$. The 
diameter of lager particles, $\mathrm{D}>5 \mu \mathrm{m}$ is on the order of the cathode spot radius. This would imply that the temperature of the large MPs would likely be greater than that of the smaller MPs, resulting in a higher charge and non-linear dependence on MP diameter, as observed experimentally.

\section{Summary}

Previous models have shown that the charge accumulated on macroparticles from a DC vacuum arc will be negative due to the high electron density. For a pulsed arc, the electron and ion densities fall after the end of the pulse, and thermionic emission dominates the macroparticle charge equation. This results in a change in the final charge of the macroparticle from a negative charge to positive. This result has been confirmed by experimental data. Comparison with experiment suggests that model refinement should be done in order to improve understanding of the MP charging mechanism in pulsed vacuum arcs. Although the electric field used in this experiment is a diagnostic tool, its effect on the final macroparticle charge will should be considered in the future.

\section{Acknowledgments}

The authors would like to thank Alameda Applied Sciences Corporation for their continued support of this research. Some hardware was provided by Michael Williams, as well as the Optical Physics Lab at UIUC. Financial support was provided by the College of Engineering at UIUC as well as the Aerospace Engineering Department. The authors would like to thank the developers of ImageJ, the freeware image analysis software used in this research. The scanning electron microscope imaging was carried out in the Center for Microanalysis of Materials, University of Illinois, which is partially supported by the U.S. Department of Energy under grant DEFG02-91-ER45439.

\section{References}

${ }^{1}$ Qi, N., Schein, J, Binder R., Krishnan, M., "Compact Vacuum Arc Micro-Thruster for Small Satellite Systems," Joint Propulsion Conference, AIAA 2001-3793, 2001

${ }^{2}$ Schein, J., Qi, N., Binder, R., Krishnan, M., Ziemer, J.K., Polk, J.E., Anders, A., "Inductive energy storage driven vacuum arc thruster," Review of Scientific Instruments, Vol. 73(2), 2002, pp 925

${ }^{3}$ M. Keidar, J. Schein, K. Wilson, A. Gerhan, M. Au, B. Tang, L. Idzkowski, M. Krishnan, I. I. Beilis, Magnetically enhanced vacuum arc thruster, Plasma Source Science \& Technology, 14, 2005, pp. 661-669.

${ }^{4}$ Anders, A., Brown, I.G., MacGill, R.A., and Dickinson, M.R. , "'Triggerless' Triggering of Vacuum Arcs," Journal of Physics D: Applied Physics, Vol. 31(7), 1989, pp 584

${ }^{5}$ Anders, A., Schein, J., Qi, N., "Pulsed vacuum-arc ion source operated with a 'triggerless' arc initiation method," Review of scientific instruments, Vol. 71, 2000, pp 827

${ }^{6}$ Tang, B., Idzkowski, L., Au, M., Parks, D., Krishnan, M., Ziemer, J., , "Thrust improvement of the Magnetically Enhanced Vacuum Arc Thruster (MVAT)," International Electric Propulsion Conference, IEPC 2005-304, 2005

${ }^{7}$ Rysanek, F., Hartman, J., Schein, J., Binder, R., "MicroVacuum Arc Thruster Design for a CubeSat Class Satellite," USU Conference on Small Satellites, SSC02-I-2, 2002

${ }^{8}$ Hantzsche, E. , "Theory of the expanding plasma of vacuum arcs," J. Phys. D: Applied Physics, Vol. 24, 1991, pp 1339

${ }^{9}$ Harris, L.P. "Arc Cathode Phenomenon" in VACUUM ARCS, Theory and Application, J.M. Lafferty Ed., New York: Wiley, 1980, p120

${ }^{10}$ Beilis, I.I., "State of the Theory of Vacuum Arcs," IEEE Transactions on Plasma Science, Vol. 29(5), 2001, pp 657

${ }^{11}$ Djakov, B.E., Holmes, R., "Cathode Spot Division in Vacuum Arcs with Solid Metal Cathodes," Journal of Physics D: Applied Physics, Vol. 4, 1971, pp 504

${ }^{12}$ Anders, S., Juttner, B., Pursch, H., Siemroth, P., "Investigaitons of the current density in the Cathode Spot of a Vacuum Arc. ," Contributions to Plasma Physics, Vol. 25(5), 1985, pp 467

${ }^{13}$ Hantzsche, E. Juttner B., "Current Density in Arc Spots," IEEE Trans. on Plasma Science, Vol. 13(5), 1985, pp 230

${ }^{14}$ Kimblin, C.W. , "Erosion and Ionization in the Cathode spot regions of vacuum arcs," Journal of Applied Physics, Vol. 44(7), 1973, pp 3074

${ }^{15}$ Daalder, J.E., "Components of Cathode erosion in vacuum arcs," J. Phys. D: Applied Physics, Vol. 9, 1976, pp 2379

${ }^{16}$ Tuma, D.T. Chen, C.L., Davies, D.K., "Erosion products from the cathode spot region of a copper vacuum arc," Journal of Applied Physics, Vol. 49(7), 1978, pp 3821

${ }^{17}$ Anders, A. Yushkov, G.Y., "Ion flux from vacuum arc cathode spots in the absence and presence of a magnetic field," Journal of Applied Physics, Vol. 91(8), 2002, pp 4824

${ }^{18}$ Hantzsche, E., "Mysteries of the Arc Cathode Spot: a retrospective Glance," IEEE Transactions on Plasma Science, Vol. 31(50), 2003, pp 799

${ }^{19}$ Boxman, R.L., Goldsmith, S. , "The interaction between plasma and macroparticles in a multi-cathode-spot vacuum arc," Journal of Applied Physics, Vol. 52(1), 1981, pp 151 
${ }^{20}$ Moizhes, B.Y., Nemchinskii, V.A., "Erosion and Cathode Jets in a Vacuum Arc," Soviet Physics Technical Physics, Vol. 25(1), 1980, pp 43

${ }^{21}$ Harris, L.P., "A Mathematical Model for Cathode Spot Operation," Proceedings VIII International Symposium on Discharge and Electrical Insulation in Vacuum, F1, 1978

${ }^{22}$ Davis, W.D., Miller, H.C., "Analysis of the Electrode Products Emitted by dc Arcs in a Vacuum Ambient," Journal of Applied Physics, Vol. 40(5), 1969, pp 2212

${ }^{23}$ Plyutto, A.A.,Ryzhkov, V.N., Kapin, A.T., "High Speed Plasma Streams in Vacuum Arcs," Soviet Physics JETP, Vol. 20(2), 1965 , pp 328

${ }^{24}$ Wieckert, C., "A Multicomponent Theory of the Cathodic Plasma Jet in Vacuum Arcs," Contributions to Plasma Physics, Vol. 27, 1987, pp 309

${ }^{25}$ McClure, G.W. , "Plasma expansion as a cause of metal displacement in vacuum-arc cathode spot," Journal of Applied Physics, Vol. 45(5), 1974, pp 2078

${ }^{26}$ Shalev, S., Boxman, R.L., Goldsmith, S. , "Velocities and Emission Rates of Cathode-Produced Molybdenum Macroparticles in a Vacuum Arc," Journal of Applied Physics, Vol. 58(7), 1985, pp 2503

${ }^{27}$ Shalev, S.,Boxman, R.L., Goldsmith, S. , "MacroParticle Dynamics During Multi-CathodeSpot Vacuum Arcs," IEEE Transactions on Plasma Science, Vol. 14, 1986, pp 59

${ }^{28}$ M. Keidar, I. Beilis, R. L. Boxman, and S. Goldsmith. Transport of macroparticles in magnetized plasma ducts. IEEE Trans. Plasma Sci., vol. 24, 1, pp. 226-234, 1996

${ }^{29}$ M. Keidar, I. Beilis, R. L. Boxman, and S. Goldsmith. Macroparticles interaction with a substrate in cathodic vacuum arc deposition, Surf. Coat. Technol., vol. 86/87, pp. 415-420, 1996

${ }^{30}$ Boxman, R., Goldsmith, S., "Principles and Applications of Vacuum Arc Coatings," IEEE Transactions on Plasma Science, Vol. 17(5), 1989, pp 705

${ }^{31}$ Keidar, M., Beilis, I.I., Aharonov, R., Arbilly, D., Boxman, R.L., Goldsmith, S.,, "Macroparticle distribution in a quarter-torus plasma duct of a filtered vacuum arc deposition system," J. Phys D: Applied Physics, Vol. 30, 1997, pp 2972

${ }^{32}$ Keidar, M., Aharonov, R., Beilis, I.I., "Influence of an electric field on the macroparticle size distribution in a vacuum arc," Journal of Vacuum Science and Technology A, Vol. 17(5), 1999, pp 3067

${ }^{33}$ Anders, A., MacGill, R.A., McVeigh, T.A., "Efficient, compact power supply for repetitive pulsed, "triggerless" cathodic arcs," Review of scientific instruments, Vol. 70(12), 1999, pp 432

${ }^{34}$ Brown, I.G., "Vacuum Arc Ion Sources," Review of scientific instruments, Vol. 65, 1994, pp 3061

${ }^{35}$ ImageJ, Software Package, Ver 1.34s, National Institute of Health, USA.

${ }^{36}$ Chapter 14-6, Metals Reference Book, Smithells, Colin J. Editor, 6th Edition, Boston: Butterworths 1983

${ }^{37}$ Chapter 2, Perry's Chemical Engineers' Handbook, Perry, R. and Green, D., $7^{\text {th }}$ Edition, New York : McGraw-Hill, 1997

${ }^{38}$ Keidar, M., Beilis, I.I., Boxman, R.L., Goldsmith, S., "Nonstationary Macroparticle Charging in an Arc Plasma Jet," IEEE Transactions on Plasma Science, Vol. 23(6), 1995, pp 902

${ }^{39}$ I. Beilis, M. Keidar, R. L. Boxman, and S. Goldsmith. Non-equilibrium macroparticle charging in low-density plasmas. IEEE Trans. Plasma Sci., 25, 1997, pp. 346-352.

${ }^{40}$ M. Keidar, I.D. Boyd and I.I. Beilis, A model of particulate interaction with plasma in a Teflon pulsed plasma thruster, $J$. Prop. Power, vol. 17 No. 1, 2001 pp. 125-131.

${ }^{41}$ I.I. Beilis, personal communication, 2006 